\title{
RESEARCH
}

\section{Socio-Demographic Profiling of Blunt Trauma Cases Autopsied at B P Koirala Instituite of Health Sciences}

\author{
Khan Abdul Sami *1, Sah Bikash ${ }^{2}$, Chataut Tej Prakash ${ }^{3}$, Prasad Shyam Babu', Rana Gopal, \\ Ansari Firoz ${ }^{5}$
}

${ }^{1}$ Department of Forensic Medicine, National Medical College, Birgunj, Nepal

${ }^{2}$ Department of Forensic Medicine, BP Koirala Institute of Health Sciences, Dharan, Nepal

${ }^{3}$ Department of Forensic Medicine, Chitwan Medical College, Bharatpur, Nepal

${ }^{4}$ Department of Anatomy, National Medical College, Birgunj, Nepal

${ }^{5}$ Department of Emergency, National Medical College, Birgunj, Nepal

Date of Submission : March 03, 2018

Received in Revised Form : March 25, 2018

Date of Acceptance : April 15, 2018

Date of Publishing : July 30, 2018

\section{ABSTRACT}

Background: Blunt trauma is a frequent emergency and is linked with significant morbidity and mortality. The World Health Organization estimates that, by 2020, trauma will be the first or second leading cause of years of productive life lost for the entire population of the world. This study focuses to evaluate 150 cases of death due to blunt trauma

Methods: A descriptive cross sectional study of 150 blunt trauma cases autopsied at department of Forensic Medicine and Toxicology of BP Koirala Institute of Health Sciences, Dharan during a period of April 2012 and April 2013 was done.

Results: Among the 150 victims of blunt trauma, 110 were of RTA, 20 were from fall from height, 15 were physically assaulted and 5 were victims from collapse of roof/wall. $80 \%$ of the victims were males and 20\% were females, the Male: Female ratio being $4: 1$.The mean age was 35.76 years, standard deviation being 17.49. 42.7\% belonged to the age group of $21-40$ years. $40 \%$ incident happened in summer with $12.7 \%$ in the month of March.33.3\% incident happened during evening hours of $3 \mathrm{pm}-6 \mathrm{pm} .42 .7 \%$ victims survived for less than 3 hours after the incident. $36.36 \%$ of RTA victims sustained injury from heavy four wheelers like buses, trucks, tractors.50\% of the falls were from the height of $21-30$ feet.53.33\% of the victims of physical assault were assaulted with hands and legs. $46.6 \%$ sustained injury to brain.

Conclusions: Research finding have shown that $80 \%$ of the victims were males and $20 \%$ were females, the male is to female ratio being $4: 1$. The mean age was 35.76 years, standard deviation being 17.49 . $42.7 \%$ belonged to the age group 21-40 years. Age group was not a significant predictor of the gender involved in the cases.

Keywords: Blunt trauma, Road traffic accidents, Fall from height, Physical assault, Victims.

*Corresponding Author: Dr Abdul Sami Khan, Department of Forensic Medicine, National Medical College, Birgunj, Nepal, E-mail: samikhan9841@ gmail.com

\section{INTRODUCTION}

Trauma or injury is defined as damage to the body due to an exchange with environmental energy that is beyond the body's resilience. ${ }^{1}$ Injury is a leading cause of death and disability worldwide. It continues as the leading cause of death in ages 1-50. There are variety of forces that can cause injury including thermal, chemical and ionizing radiation. However the force in most of the injuries is mechanical. The subject of trauma therefore centers upon the deleterious effects of 
kinetic energy on the human body frame. ${ }^{2}$ Injury accounts for $9 \%$ of global mortality, and are a major threat to health in every country. ${ }^{3}$ During the first five decades of life, trauma is an important cause of ever increasing mortality and morbidity. Since it involves the most active group of the human population, improvement in trauma care and prevention of avoidable deaths are among the important goal of health care establishments of many countries. ${ }^{4}$ The term accident is defined as an occurrence in the sequence of events which usually produces unintended injury, death or damage to property. Accidents have their own natural history and they follow the same epidemiological pattern as any other disease that is, the agent, the host and the environmental factors interacting together to produce injury, death or damage. ${ }^{5}$ There are overall 885,000 deaths from road traffic accidents annually and total number of causalities goes around 10 million. Studies done by World Health Organization show that road traffic accidents account for $2.5 \%$ of total deaths occurring worldwide. But in age group of 5-44 years, it is almost $10 \%$ and is one of the six leading cause of death. ${ }^{6}$ Injuries due to RTA depend upon a number of factors-human, vehicle and environmental which altogether play a major roles before, during and after serious accidents. Some of the major factors involved in an accident are human errors, driver fatigue, poor traffic knowledge, mechanical fault in vehicle, excessive speeding and overtaking, violation of traffic rules, bad road conditions, traffic congestion, road encroachment, drunkenness and driving, etc. ${ }^{7}$ The rationale of this study was to analyze the pattern of socio demographic variation among blunt trauma cases which were brought for Medico-legal autopsy in the mortuary of the Department of Forensic Medicine, BP Koirala Institute of Health Sciences.

\section{MATERIALS AND METHODS}

A descriptive cross sectional study of 150 blunt trauma cases autopsied at department of Forensic Medicine and Toxicology of BP Koirala Institute of Health Sciences, Dharan during a period of April 2012 and April 2013 was done. All the autopsies showing blunt trauma injuries either died on the spot or on the way to the hospital and all those cases of blunt trauma injuries that were hospitalized following accident and subsequently died due to their injuries were included in the study. The bodies that were decomposed were excluded from the study. Data was collected systematically in a detailed Performa developed for the postmortem evaluation of blunt trauma injuries. The detailed information about the cases were collected from different sources including:

The inquest report and other relevant papers brought by the police.

Interviews of the police personnel accompanying the dead body.

Interviews of the relatives, neighbors, friends or other persons accompanying the dead body.

Relevant clinical history and findings upon admission in hospital.

\section{Detailed post-mortem examination}

All the datas that were collected was compiled and entered into the Microsoft Excel. Analysis was done using Statistical Package for Social Sciences version 17.0. Observations were recorded, analyzed and discussed. Ethical clearance was obtained from the Ethical Committee of the institute.

\section{RESULTS}

A total of 496 postmortem examinations were done in the Department of Forensic Medicine and Toxicology in between April 2012 and 2013. 150 were victims of blunt trauma injury and among them, 110 were from RTA, 20 were from fall from height, 15 were from physical assault and 5 victims were due to collapse of roof/wall. Table 1 shows the distribution of different age groups of the victims. The minimum age was 4 years and maximum 76 years. The mean age was 35.76 years with standard deviation of 17.49. $42.7 \%$ of the victims were in the age group 21-40 years. $26.7 \%$ of the victims were in the age group of 21-30 years. 31-40 years age group contained $16 \%$ victims. $41-50$ years group comprised of $14.7 \%$ victims. The age group of $11-20$ comprised $10 \%$. Victims that belonged to more than 50 years age group made $24.7 \% .80 \%$ of the victims were males and females accounted for only $20 \%$, with male is to female ratio of $4: 1$. 
Table 1: Age of the victims

\begin{tabular}{|c|c|c|}
\hline Age Range (Years) & Number(victims) & Percentage \\
\hline $0-10$ & 12 & $8 \%$ \\
\hline $11-20$ & 15 & $10 \%$ \\
\hline $21-30$ & 40 & $26.7 \%$ \\
\hline $31-40$ & 24 & $16 \%$ \\
\hline $41-50$ & 22 & $14.7 \%$ \\
\hline $51-60$ & 15 & $10 \%$ \\
\hline$>60$ & 22 & $14.7 \%$ \\
\hline Total & 150 & $100 \%$ \\
\hline
\end{tabular}

$27.33 \%$ of the cases occurred during rainy months of July, August, September and October and 40\% of the cases occurred during summer months of March, April, May and June followed by $32.66 \%$ of cases in winter months of November, December, January and February. (Figure 1)

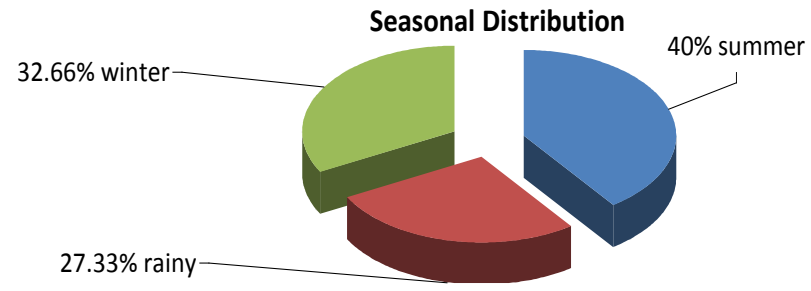

Figure 1 : Seasonal distribution of Incident

Most of the incidents occurred between 3 pm- 6 pm (33.3\%) followed by 12 pm-3 pm (22.7\%), 3 am-6 am (4\%) and 12 am- 3 am (2.7\%). Maximum number of incident took place in the month of March (12.7\%) and minimum in October (5.3\%).

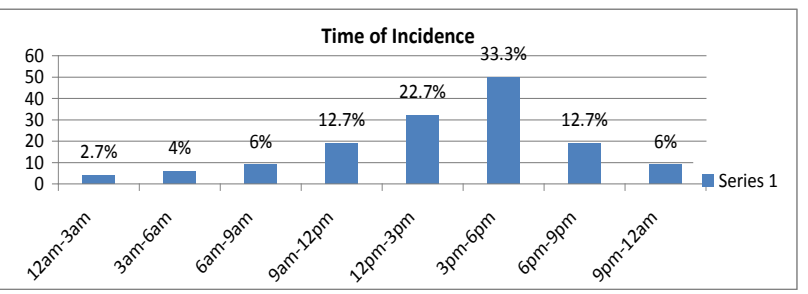

\section{Figure 2: Time of Incidence}

$42.7 \%$ of the victims survived for less than 3 hours whereas only $6 \%$ of the victims survived for 1-3 days.

\section{Table 2: Survival Period}

\begin{tabular}{|c|c|c|}
\hline Survival Period & Number (victims) & Percentage \\
\hline$<3$ hours & 64 & $42.7 \%$ \\
\hline 3-6 hours & 41 & $27.3 \%$ \\
\hline 6-24 hours & 20 & $13.3 \%$ \\
\hline 1-3 days & 9 & $6 \%$ \\
\hline 3-7 days & 16 & $10.7 \%$ \\
\hline
\end{tabular}

Large number of victims of blunt trauma were due to road traffic accidents $(73.3 \%)$ while victims of fall from height comprised $13.3 \%, 10 \%$ of victims were of physical assault and only 3.3\% of the victims suffered trauma due to collapse of roof/wall.(Table 3)

Table 3: Cause of Trauma

\begin{tabular}{|l|c|c|}
\hline Cause of Trauma & Number (victims) & Percentage \\
\hline Road traffic accident & 110 & $73.3 \%$ \\
\hline Fall from height & 20 & $13.3 \%$ \\
\hline Physical assault & 15 & $10 \%$ \\
\hline Collapse of roof/wall & 5 & $3.3 \%$ \\
\hline Total & 150 & $100 \%$ \\
\hline
\end{tabular}

Heavy four or more wheelers like trucks, buses, tractors etc accounted for $36.36 \%$ of the accidents whereas two wheelers accounted for $35.45 \%$ and the least were three wheelers $0.7 \%$.( Figure 3 )

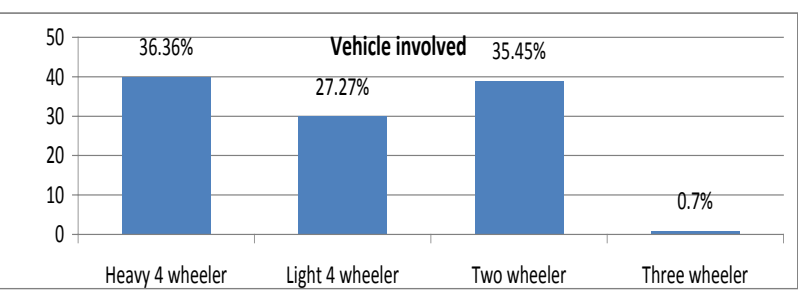

Figure 3: Vehicle involved in victims of RTA

$50 \%$ of cases of fall from height fell from a height of 21-30 feet whereas only 5\% case was found to have fallen from 40-50 feet height(Table 4). Most of the victims of physical assault were beaten by hands and legs $(53.33 \%)$ whereas iron rods and wooden sticks and bamboos were also used to assault the victim.

Table 4: Height of fall in victims of fall from height

\begin{tabular}{|c|c|c|}
\hline Height of Fall & Number (victims) & Percentage \\
\hline $10-20$ feet & 6 & $30 \%$ \\
\hline $21-30$ feet & 10 & $50 \%$ \\
\hline $31-40$ feet & 3 & $15 \%$ \\
\hline $40-50$ feet & 1 & $5 \%$ \\
\hline Total & 20 & $100 \%$ \\
\hline
\end{tabular}

\section{DISCUSSION}

This study was conducted among the victims of blunt trauma injury related death brought for autopsy in the mortuary of BPKIHS. In Nepal the available data for morbidity and mortality of the year 1998-1999 shows that injury contributed $9 \%$ to total mortality and was the third leading cause of death. Road traffic accidents related deaths occupied the eighth position in the overall ranking. Fifty eight per cent of the injuries 
occurred in the age group of 15-44 years with the male is to female ratio of $3: 1 .^{8}$ Various studies on different types of roads and causalities involved showed that most of the victims happened to be pedestrians followed by motorcycle riders ${ }^{9}$.

The most vulnerable age group in our study was 21 to 30 years that comprised $26.7 \%$ of the total cases followed by $31-40$ years $(16 \%)$. This age group is more active, productive and are at the peak of their creativity having the tendency to take risk, alcoholic intoxication etc. thereby are prone to the dangers of accidents and injuries. Fatalities due to blunt trauma injury were maximum in the age group of 21-40 years $(40.63 \%)$ in Gambhir et al ${ }^{10}$ study. Putul Mahanta $^{11}$, Banerjee et al ${ }^{12}$ also showed similar results. The involvement of economically productive age groups in accidents causes a serious economic loss to the country and hence requires the development of necessary strategies to prevent and control the accidents.

It was noticed that children below 10 years were less commonly involved comprising $8 \%$ of victims. The reason could be that children are taken care of by elders with extra caution while taking out and also are less likely to use vehicles thus less likely exposed to fatally injurious events. The proportion of victims in those aged 60 years and above being $14.7 \%$ could be due to the generally decreased protective response to probable sudden oncoming encounter to vehicles or any oncoming accidents.

Males were predominant over females in our study with male: female ratio being $4: 1$. The reason behind this could be that males are usually the earning members of the families which make them more mobile and vulnerable to accidents as compared to females who are generally indulged in household chores. The involvement of males in violence, sports, consumption of alcohol and drugs more often than females makes them more vulnerable to accidents. In similar studies done by Gambhir et $\mathrm{al}^{10}$ found male to female victim ratio of 3.2:1. In most of the other studies male prevalence was higher compared to female.
Most of the incidents occurred between $3.00 \mathrm{pm}$ $6.00 \mathrm{pm}(33.3 \%)$ followed by $12.00 \mathrm{pm}-3.00 \mathrm{pm}$ $(22.7 \%) ; 12.7 \%$ each in case of $9.00 \mathrm{am}-12.00 \mathrm{pm}$ and $6.00 \mathrm{pm}-9.00 \mathrm{pm}$. Only $2.7 \%$ incident occurred during 12.00am-3.00am. The studies conducted by Menon $\mathrm{A}^{13}$ and Banthia $\mathrm{P}^{14}$ have shown most of the accidents happened during the afternoon and evening hours. Oberoi $\mathrm{SS}^{15}$ reported most of the fatal accidents (46\%) occurred in the evening hours followed by $22 \%$ occurring at night. The common occurrence of vehicular accidents in the evenings is well supported by the findings in a study from Pokhara, Nepal by Mishra et $a^{16}$ who showed maximum number $(44.16 \%)$ of accidents took place in between 3 and 7 p.m. Gururaj ${ }^{17}$ studied that the alcohol consumption in evening and night time led to most number of accidents. The reason behind this trend of accidents may be when the people are rushing back to their home during the evening or twilight hours, the visibility is getting progressively poorer with the night fall. In contrast to our study, in a study from Delhi, India by Akash $^{18}$ showed most of the vehicular accidents happened between 9:01pm - 12:00am which amounted to $18 \%$ of total cases, followed by the period of 6:01pm - 9:00pm during which $15 \%$ of all accidents took place. In a study from Gauhati, India, Putul ${ }^{11}$ showed the most common time of accidents was between 9:00am to 12:00 am.

Maximum of the incidents occurred during March (12.7\%) followed by February, April, November $10 \%$ each. Least number of incident was in October (5.3\%). $27.3 \%$ of the incidents occurred during rainy months of July, August, September and October and $40 \%$ in the summer months of March, April, May and June and 32.7\% in the winter months of November, December, January and February. In contrast to our study, study done by Kumar et $\mathrm{al}^{19}$, majority of fatal accidents took place in winter months.

Vehicles were determined in cases of accidents involving two or more vehicles. Most common vehicles were heavy four wheelers i.e. trucks, buses, tractors that constituted $36.36 \%$ cases followed two wheelers like motorbike (35.45\%); light four wheelers like cars, jeeps were involved in $27.27 \%$ and three wheelers in $0.7 \%$. Involvement of Redline buses (38\%) followed 
by trucks $(16 \%)$ was shown by Akash. ${ }^{18}$ Jha and Agrawal ${ }^{20}$ showed Buses (31.4\%), trucks $(12.3 \%)$ were commonly involved. The results are similar to our study. Higher involvement of buses and trucks in RTA was shown by, Mishra $\mathrm{B}$ et $\mathrm{al}^{16}$, Putul Mahanta ${ }^{11}$. The size of the vehicle and its difficulty in handling might have caused those vehicles to be more prone to the accidents.

13.35 victims were due to fall from height and among them 50\% fell from $21-30$ feet height,30\% fell from 11-20 feet height and only 5\% fell from 41-50 feet. Anil Kohli ${ }^{21}$ in his study of fatal falls from building found maximum cases fell from 10-20 feet.In physical assault related deaths $53.3 \%$ had injuries from bodily parts of offender (hands and legs). In a study relating to physical violence by Sandra L Martin et $\mathrm{al}^{22}$ maximum use of hands and legs as physical means of violence.

There were some limitations of the Study. The study was confined to the victims that were brought for medico legal autopsy in the mortuary of BPKIHS only. The broader picture could have been obtained if it were extended to the other centers of the region also. The study period was of one year only which could have been extended to obtain better results. The time of survival could not be elicited precisely in some cases as the relatives, accompanying persons or bystanders were sometimes unaware of the exact time of incidence and death.

The study was based on the observation of 150 victims showing blunt trauma related injuries, that were autopsied in the mortuary of the Department of Forensic Medicine \& Toxicology, BPKIHS, Dharan during the period of $1^{\text {st }}$ Baisakh 2069 to $30^{\text {st }}$ Chaitra 2069 (13 $^{\text {th }}$ April 2012 to $13^{\text {th }}$ April 2013). The salient observations that have emerged out of the study are as follows:

- $80 \%$ of the victims were males and $20 \%$ were females, the male is to female ratio being $4: 1$.

- The mean age was 35.76 years, standard deviation being $17.49 .42 .7 \%$ belonged to the age group 21-40 years.

- Age group was not a significant predictor of the gender involved in the cases.

- $40 \%$ incident happened in summer with $12.7 \%$ in the month of March.

- $33.3 \%$ incident happened during evening hours of $3 \mathrm{pm}-6 \mathrm{pm}$.
- $42.7 \%$ victims survived for less than 3 hours after the incident.

- $73.3 \%$ of victims sustained trauma due to road traffic accident while $26.7 \%$ were victims of fall from height, physical assault and collapse of roof/wall.

- $36.36 \%$ of RTA victims sustained injury from heavy four wheelers like buses, trucks, tractors.

- $50 \%$ of the falls were form the height of 21 30 feet.

- $53.33 \%$ of the victims of physical assault were beaten by hands and legs.

\section{CONCLUSION}

Following recommendations can be made as concluding the article.

\section{Measures of Motor Vehicle Injury Control} (Haddon's Countermeasures with examples) ${ }^{23}$

- Prevention of creation of agent: Reduce the manufacture of particularly dangerous motor vehicles. Prohibit modification of vehicles that deteriorates the original dynamics, making the vehicle prone to accident.

- Reduction of amount of Agent: Vehicle engineering to prevent crashes; reduce the amount of argentous drivers, eg. Laws against driving under the effect of alcohol intake, issuing driving license to the properly trained and educated persons only, and frequent awareness programs and refreshers training courses to those concerned.

- Prevention of release of agent: Reduce speed limits. Develop effective speed policies for different regions along with using proper scanning cameras installed at strategic and accident prone spots capable to detect speed for speedy and rash driving incidents.

- Modification rate or spatial distribution of agent: Alternative transportation to limit the amount of vehicles in use.

- Separation of the agent from susceptible host in time and space: Prevent pedestrians and bicyclist from vehicle traffic by use of bike lanes, pedestrian over passes and sidewalks. Prohibit the use of inadequately maintained vehicles and the vehicles with ineffective lights in the night time. 
- Separation of the agent from the susceptible host by interposition of a material barrier: Design, improved vehicle safety mechanism, for example seatbelts and airbags.

- Modification of qualities of the agent: Design vehicles to reduce injuries, e.g. shatterproof windows, more absorbent bumpers, better fire retardant materials, and more foot room.

- Strengthening of the susceptible host: Increase public awareness e.g. pedestrian education and drinking driving agents. Begin to counter the injury already done by the agent: Train local volunteers to improve both quantitative and qualitative first-aid services. Provide adequately trained paramedics and well equipped ambulances. Train medical staff and emergency medical services to respond quickly and appropriately to the crash and the injuries.

- Beginning to counter the injury already done by the agent: Train medical staff and emergency medical services for quick and appropriate response to crash and injuries.

- Stabilization, repair and rehabilitate the injured host: Improve rehabilitation services.

\section{Fall from height, preventive measures.}

- Safety of the houses should be ensured by securing the boundary of roof and balcony by proper railings.

- Safety measures for workers in high rise buildings should be ensured.

- Proper mountain trails constructed to ensure the safety of people walking in mountain from one village to another.

- Preventing old person and children living in mountainous terrain from exploring more at evening and night.

- Strict control in alcohol consumption.

\section{REFERENCES}

1. Brunicardi C, Anderson DK, Billiard TR, Dunn DL, Hunter JG, Pollock RE. Schwartz's Surgery. $8^{\text {th }}$ ed. The McGrawHill; 2007.

2. Williams NS, Bulstrode CJK, O'Connell PR, editors. Bailey and Love's short practice of surgery. $25^{\text {th }}$ ed. London: Arnold; 2008. P. 271.
3. Peden M, McGee K, Sharma G. The injury chart book: a graphical overview of global burden of injuries. Geneva, World Health Organization, 2002.

4. Rabbani A, Moini M, Application of "Trauma and Injury Severity Score" and "A Severity Characterization of Trauma" Score to trauma patients in a setting different from "Major Trauma Outcome Study". Archives of Iranian Medicine. 2007; 10(3): 383-386.

5. Park K. Park's Textbook of preventive and Social Medicine, $18^{\text {th }}$ ed. Jabalpur; Banarsi Das Bhanot; 2005 p.323.

6. Singh H, Dhattarwal S.K., pattern and distribution of injuries in fatal road traffic accidents in Rothak. JIAFM. 2004; 26(1) 0971-0973.

7. Kaul A, Sinha A, Kaporr A.K., Sharma S, Fatal road traffic accidents, study of distribution, nature and type of injury. JIAFM 2005; 27 (2). 0971-0973.

8. Epidemiological Study on Injury and Violence in Nepal, Conducted by Nepal Health Research Council (NHRC) Ram shah Path Kathmandu. 2009.

9. Keshab K. Sharma Status Paper on road safety in Nepal, 2011. Www.unescap. Org/ ttdw/ ...Road safety--/ Status/--/ Nepal2010- status - paper.

10. Singh OG, Gupta BD, a profile of fatal head injury in homicidal deaths. Indian Internet journal of forensic medicine \& Toxicology. 2010; 8(2):0973-1970.

11. Mahanta P. Study of abdominopelvic injuries in victim of road traffic accident. International journal of medical toxicology and legal medicine. 2010.12(3): 24-31.

12. Banerjee KK, Aggrawal BBL, Kohli A. Study of thoraco abdominal injuries in fatal road traffic accidents in Northern East Delhi. JFMT15(1):40-43.

13. Menon A, Pai VK, Rajeev A Pattern of fatal head injuries due to vehicular accidents in Mangalore. J Forensic Leg Med. 2008; 15: 75-7. 
14. Banthia P, Koirala B, Rauniyar A, chaudhary A, Kharel T, Khadka SB. An epidemiological study of road traffic accident cases attending emergency department of teaching hospital. J Nepal Med Assoc. 2006:45:238-43.

15. Oberoi SS, Aggarwal KK, Walia DS, Kumar R. Sandhu Harjesus. Profile of fatal two wheeler Accident cases. J Punjab Acad Forenic Med Toxicol. 2010; 10.2.

16. Mishra B, Sinha N, Sukhla S, and Sinha A. Epidemiological Study of Road Traffic Accident Cases from Western Nepal. Indian J Community Med. 2010; 35(1):115-121.

17. Gururaj G. The effect of alcohol in Incidence, Pattern, Severity and outcome from traumatic brain injury. J Indian Med Assoc. 2004; 102(3): 157-60,163.

18. Jhanjee A. A Post mortem study of abdominal injuries and pelvic trauma in Central Delhi. Anil Aggrawal's internet journal of forensic medicine and toxicology [serial online]. 2000 July-Dec [cited 2010 Feb 4]; 1(2)1. Available From URL: htttp:// www. geradts.com/anil/ij/indexpapers. html.
19. Kumar A, Lalwani S, Agarwal D, Rautji R, Dogra TD. Fatal road traffic accidents and their relationship with head injuries: An epidemiological survey of five years. IJNT. 2008; 5:(2): 63-7.

20. Jha N, Aggrawal CS. Epidemiological Study of Road Traffic Accidents Cases: A study from Eastern Nepal. 2004; 8(1).

21. Kohli A. Pattern of Injuries in fatal fall from buildings. JIAFM. 2005:27(1):0971-0973.

22. Martin S L, Moraccoa K E, Garrod J, et al. Domestic violence across generations: findings from northern India. International journal of epidemiology. 31(3):560-72.

23. Haddon W. Options for the prevention of motor vehicle crash injury. Isr J Med Sci. 1980;16:45-68. 